\title{
Mobile Virtual Reality Distraction Reduces Needle Pain and Stress in Children
}

\author{
Joanna Ewa Piskorz ${ }^{1}$ Marcin Czub¹, Beata Šulžickaja1, \& Katarzyna Kiliś-Pstrusińska² \\ ${ }^{1}$ Institute of Psychology, University of Wroclaw, Wroclaw, Poland \\ 2 Dept. of Paediatric Nephrology, Wroclaw Medical University, Wroclaw, Poland
}

\begin{abstract}
Virtual reality (VR) technology is a remarkably effective method for distracting attention from painful stimuli. This is particularly important for children who undergo painful and stressful medical treatments. The main aim of the present study was to examine whether the type of $V R$ distraction had an effect on reducing pain and stress in children during a short blood sampling treatment, and to investigate the effectiveness of mobile $V R$.

Fifty-seven patients of a pediatric nephrology clinic ( $M_{\text {age }}=12$, range: $7-17$ ) participated in a between-group experimental design study. Participants in the treatment group (active vs passive VR) underwent a venipuncture procedure with VR distraction. Mobile VR (Samsung gear) was used in this study. Participants in the active VR experimental condition played a game based on the multiple object tracking task paradigm. In the passive VR experimental condition, participants watched a film similar to the presented game. All participants rated their pain and stress levels on the Visual Analogue Scale and completed a short questionnaire.

Both VR groups reported significantly lower pain and stress intensity than the control group. When comparing the two experimental groups, no statistically significant differences were found, although participants differed in their level of perceived pain and stress, with greater benefits in the active VR. The present study focused on comparing the effect sizes of active and passive VR interventions. Additionally, the study confirmed feasibility of using Multiple Object Tracking paradigm as a method of attention distraction in VR.
\end{abstract}

Keywords: Children; pain; acute care; virtual reality; analgesia

\section{Introduction}

The perception of pain is greatly affected by psychological factors. According to the neuromatrix model (Melzack, 2001), pain is a multidimensional experience, which consists of sensory, affective, and cognitive components. These components are mediated by different brain regions and shaped by several inputs that act on the neuromatrix and contribute to the output neurosignature.

Among the factors that can affect sensations of pain, the attention directed to pain appears to be particularly important. Therefore, distraction is considered a useful way to ease pain (Eccleston \& Crombez, 1999; McCaul \& Malott, 1984). Existing research has demonstrated the analgesic properties of various distraction techniques, including cognitive tasks, relaxation, watching films, and nurse coaching (Triberti et al., 2014). Attention distraction techniques have proven effective both in children (Fowler-Kerry \& Lander, 1987; Kelley et al., 1984; Manne et al., 1990; Powers et al., 1993) and adults (Villemure \& Bushnell, 2002).

Recent evidence has shown that virtual reality (VR) technology is an extremely effective method for distracting attention from painful stimuli, allowing an individual to experience being immersed in-and feel present in-a simulated 
environment (Triberti et al., 2014). VR allows for isolating from the real world in which one experiences pain and focusing on pleasant virtual experiences, thereby relieving stress and anxiety (Schneider \& Hood, 2007). Research confirms that the level of anxiety and stress can increase the perception of pain (Gatchel et al., 2007; Ploghaus et al., 2001). In addition, VR technology has the property of inducing positive emotions, which also promote lowered pain perception (Triberti et al., 2014).

The effectiveness of VR has been demonstrated in a large number of studies carried out both in healthy populations (Czub \& Piskorz, 2018; Hoffman et al., 2003; Hoffman, Richards et al., 2006; Kenney \& Milling, 2016; Magora et al., 2006) as well as among hospital patients during medical procedures such as burn injury treatments (Hoffman et al., 2011), chemotherapy (Chirico et al., 2016a), and other painful and stressful procedures-dental treatment and urology procedures (Indovina et al., 2018) and needle-related procedures (Birnie et al., 2014; Cohen et al., 2014; Gold \& Mahrer, 2017; Goodenough et al., 1997; MacLaren \& Cohen, 2005; Mason et al., 1999; Piskorz \& Czub, 2018).

Apart from lowering reported pain intensity, VR distraction may also influence perceived duration of the medical procedure (Chirico et al., 2016b; Schneider et al., 2011). This effect is explained using framework of pacemakeraccumulator model of time perception.

There are several dimensions in which distraction techniques vary-for example, the amount of interaction that the child requires. The efficacy of distraction, according to theoretical descriptions, is dependent on its ability to exploit cognitive capacity. Distraction appears to be more effective when it requires the child to be engaged, for instance by manipulating the environment and/or problem-solving. Such tasks require more use of attentional resources than passive tasks (MacLaren \& Cohen, 2005). Distraction can therefore be divided into two categories: active and passive. In their research, Nilsson et al. (2013) found that the use of serious gaming resulted in reduced behavioral pain scores when compared to passive distraction. Similar conclusions were reached by Dahlquist et al. (2007).

The reduction of pain during painful medical procedures is especially important in the case of children. Medical procedures can be a severely traumatizing experience for a child (Fradet et al., 1990; Jacobson et al., 2001). Additionally, pharmaceutical analgesics are not always recommended and might even be harmful (National Academies of Sciences, Engineering, and Medicine, 2017). Existing research confirms the analgesic properties of VR during needle-related procedures (Gershon et al., 2004; Gold \& Mahrer, 2017; Windich-Biermeier et al., 2007; Wolitzky et al., 2005) and acute burn injuries (Chan et al., 2007; Das et al., 2005; Jeffs et al., 2014) in both children and adolescents.

\section{VR and Needle-Related Procedure in Children}

One of the first studies utilizing VR during a port access procedure was conducted by Gershon et al. (2004). They used VR technology to divert attention in seven 19-year-old oncologically ill children, demonstrating that it effectively reduced both stress and pain in younger patients. Similar results were obtained a year later by Wolitzky et al. (2005). WindichBiermeier et al. (2007) did not obtain such unambiguous results. Using VR distraction, they managed to reduce anxiety and stress in children; however, pain remained at the same level.

Gold et al. (2006) also found no reduction in pain symptoms. Using VR distraction during pediatric intravenous placement, Gold et al. found no reduction in affective pain or anticipatory anxiety for children and their parents. However, children in the control group reported a fourfold increase in pain during the procedure, whereas in the VR group, this effect was not observed. Some existing studies do not confirm VR as an effective method for distracting attention from pain sensations in children. One example comes from Nilsson et al. (2009). Their study, however, relied on non-immersive VR (3D, hand-controlled VR devices, without head-mounted displays) during a needle-related procedure in oncologically ill children.

The discrepancies found in the studies discussed may be due to the use of older VR technology. The quality of equipment is very important because it affects the degree of immersion in the virtual environment (cf. Hoffman et al., 2004; Hoffman, Seibel et al., 2006). In addition, in all of the discussed studies, the game was controlled using a joystick or mouse; that is, it required the mobility of one hand, which prevents its use for distraction purposes during many medical procedures. Recent research confirms the effectiveness of VR in reducing pain during painful medical procedures. Using VR mobile technology, Gold and Mahrer (2017) demonstrated that VR significantly reduced anxiety and acute procedural pain compared with the standard of care in children and adolescents aged 10 to 21 . Current study extends on those findings by comparing the effectiveness of active and passive VR interventions, and implementing a novel VR distraction task. 
Another reason may be related to the types of virtual environments, some of which may not be suitable for certain children. In their research, Windich-Biermeier et al. (2007) allowed children to choose the type of distraction freely, including the level of sensory input as well as the ability to involve active cognitive or motor responses. Gershon et al. (2004) and Wolitzky et al. (2005) used the existing Virtual Gorilla application, which was created as an educational tool for children visiting the gorilla habitat at Zoo Atlanta (Allison et al., 1997). Similarly, Gold et al. (2006) relied on the already existing game Street Luge, whereas Gold and Mahrer (2017) used the game Bear Blast.

In their previous work, the authors of the present study demonstrated the analgesic efficacy of VR during blood sampling in children (Piskorz \& Czub, 2018). The results of their experiment revealed a significant reduction in both pain and stress when compared with the stand-of-care group. During the blood sampling procedure, participants aged 7 to 17 played a game designed by the authors based on the multiple object tracking (MOT) paradigm. MOT is based on continuous sustained attention over time rather than brief attentional shifts. It requires attention to multiple objects over focal attention to only a single object at one time. Instead of mere passive observation, MOT requires active engagement. Moreover, it can be manipulated not only via indirect temporal manipulations, but also through direct manipulation of the underlying tracking load. MOT is considerably different from most other paradigms that have been used to study attention (Scholl, 2009). It has been used in various studies on visual cognition, such working memory (Fougnie \& Marois, 2006; Postle et al., 2005), task switching (Alvarez \& Scholl, 2005), and dual-task interference (Fougnie \& Marois, 2006; Trick et al., 2006). There is evidence that people can cast a wide range of attention for MOT in a real 3D environment (Rehman et al., 2015). In addition, MOT has been employed to study the operation of attention across populations, including small children (O'Hearn et al., 2005).

The present study is a continuation of the previous one. The main aim of the study was to examine whether the type of VR distraction has an effect on reducing pain and stress during a short procedure such as blood sampling; that is, how much of the effect obtained in the previous study was accounted for by VR interaction and the game itself, and how much was related to simply cutting off external stimuli? Therefore, main objective was to compare the effectiveness of active vs passive VR interventions.

The second aim was to compare the obtained effect sizes with those found in the previous study, in which a stationary VR technology was utilized. Additionally, we wanted to further investigate feasibility of using multiple object tracking paradigm as a method of attention distraction in VR.

\section{Methods}

\section{Participants}

The study was comprised of 57 children aged 7 to 17, who were patients at the Pediatric Nephrology Clinic in Wrocław. The experiment was conducted with three study groups: two experimental and one control group. The first experimental group (active VR) was comprised of 19 children $\left(M_{\text {age }}=12.42, S D=2.52\right)$, including 10 females $\left(M_{\text {age }}=13.3, S D=2.06\right)$ and nine males $\left(M_{\text {age }}=11.44, S D=2.74\right)$. The second experimental group (passive VR) was comprised of 17 children $\left(M_{\text {age }}=11.71, S D=2.8\right)$, including 10 females $\left(M_{\text {age }}=12.20, S D=3.46\right)$ and seven males $\left(M_{\text {age }}=11, S D=1.53\right)$. The control group included 21 participants $\left(M_{\text {age }}=11.86, S D=3.81\right)$, including 10 females $\left(M_{\text {age }}=11.5, S D=3.84\right)$ and 11 males $\left(M_{\text {age }}=12.18, S D=3.95\right)$. A priori power analysis was conducted with $G * P o w e r$. It was determined that a sample of 66 was necessary to detect large effect size $(f=0.4)$ with the power of 0.8 . During data collection we aimed at a sample of 66 participants, however smaller sample was finally collected and there were minor differences in group sizes - because of participants availability in the hospital, and the time frame of the study.

\section{Design/Procedure}

The study was conducted in the Pediatric Nephrology Clinic in Wrocław. Children staying in the hospital suffer from kidney failure, and therefore stay under regular medical supervision. The study was conducted from September 2017 to February 2018. The study received approval from the institutional ethics committee of the relevant university. Written consent was collected from parents or caregivers and also verbal consent was obtained from children. All participants were informed that they may cancel participation at any moment without giving justification. Basic information about VR technology and the procedure was provided at this stage to both parents and children. 
The experiment was carried out during a blood sampling procedure. Both children who stayed in the hospital and those who came for check-ups were invited to take part in the study. Possibility of participation was offered to all children staying at the hospital, this was done until sample was completed. Depending on the research condition, relevant details of the study procedure were explained to participants. As a result, in the experimental condition active VR, children became acquainted with the VR technology and learned to play the game before making the final decision to join the study. The training lasted 10 to 15 minutes; the time depended on the rate at which children learned to control the game. In the experimental condition passive VR, children were informed that they would be equipped with VR goggles to watch a fragment of the video during blood sampling, whereas children in the control condition heard that they would be asked to fill out a short questionnaire before and after blood sampling. The children then decided whether they wanted to take part in the study during the next blood sampling.

Those who decided to participate in the study were asked to complete a short questionnaire just before the blood collection. Participants in the experimental groups were equipped with VR equipment and started to play or watch the film before the blood sampling procedure began. After leaving the treatment room, children were asked to complete the second part of the questionnaire, in which they were asked about their experiences related to the blood sampling procedure. The entire procedure lasted between 10-15 minutes. The order of both VR conditions was counterbalanced.

The control group consisted of children who underwent blood sampling without immersion in VR. Before and after leaving the treatment room, they were asked to fill out the same short questionnaire as children in the experimental group. Data for the control group was collected after completion of the VR group. This was for two reasons. First, we did not want to take away the possibility of using VR from children who would be interested in it during blood sampling. Second, we did not want to include children who did not decide to use VR during blood sampling in the control group. The reason for their refusal could be that they did not perceive this medical procedure to be painful, which ultimately could have affected the obtained results.

\section{Materials and Equipment}

Participants participated in the game using head-mounted displays (Samsung gear). They played a game created by the authors of the study. The game was based on the MOT paradigm. The game was designed for use with children of all ages. The aim of the game was to memorize blinking elements and search for them among other moving objects. Each of the game levels differed in degree of difficulty, which could be freely manipulated and thus adapted to the level of advancement of the players. To adjust the level of the game to the needs of the participant, we manipulated the number of flying objects and the number of objects that had to be remembered. The criterion for game adjustment for each participant was maximum level achieved during the training phase. This was done by the experimenter. The game is controlled without the use of hands, only by head movements and selecting the object through holding it in the center of the field of vision for a specified time. In the case of a properly solved task, participants proceeded to the next level, and in the case of error, they repeated the task.

In the passive VR condition, participants only observed the image, in which flying objects (balls) were moving. The application for this condition was selected to maximally resemble the active VR version. We opted not to present the recorded version of the active VR game for fear that it could be too wearisome, which would have affected the study results.

Participants were not listening to any music in either active or passive VR conditions. Such solution was used, because we did not want to disturb verbal communication between the nurses and patients.

\section{Measures}

Before the study began, children filled out a short questionnaire. It consisted of questions about previous experience with the blood sampling procedure, which were anchored to a 6 -point scale $(1=$ inexperienced to $6=$ very experienced $)$; attitude towards blood sampling; and, in the VR groups, attitude towards blood sampling with VR glasses. Both variables were assessed on an 11-point scale $(0=$ strong stress and tension and $10=$ strong interest/curiosity). The questionnaire was created by the authors for the purpose of this study.

After completion of the blood sampling procedure, participants answered more questions. Two questions were asked to estimate the levels of pain and stress participants experienced during the medical procedure. Children responded to a 
measure of pain and stress intensity, the Visual Analogue Scale, which includes a horizontal $10 \mathrm{~cm}$-long continuous line, where $0=$ no stress/pain and $10=$ very severe stress/pain. The next question concerned children's perceived duration of the procedure. Participants were able to choose from one of five responses: much shorter than usual, shorter than usual, just as usual, longer than usual, and much longer than usual. In the experimental groups, children answered an additional question about the degree of engagement in the VR application $(0=$ the recording did not engage me at all to $10=$ the recording absorbed me very much).

\section{Data Analysis}

Data analysis relied mostly on non-parametric statistics (Kruskal-Wallis test, Spearman's rank correlation coefficient) due to the lack of normality in the variable distributions (as indicated by the Shapiro-Wilk test) or in the ordinal level of variable measurement. For the items "Attitude towards blood sampling in VR" and "Degree of involvement in the VR application," parametric statistics ( $t$ tests) were used. We computed Hedges $g$ effect sizes and confidence intervals using the adjusted bootstrap method, with the BootES R package (Version 1.2) (Kirby \& Gerlanc, 2013).

\section{Results}

\section{Group Characteristics and Between-Group Differences}

ANOVAs revealed no significant differences among the groups (control, passive distraction, active distraction) based on participants' age, $F(2,54)=0.27, p=.77$, or their prior experience with the blood sampling procedure (Kruskal-Wallis one-way ANOVA on ranks $H[2,57]=3.78, p=.15)$. All groups were characterized by an above-average level of experience with blood sampling. The experimental groups did not differ in the assessment of the degree of engagement in VR, $t(4)$ $=-0.09, p=.93$. Both groups found the VR environment to be highly engaging (active VR: $M=6.18, S D=2.76$; passive VR: $M=6.26, S D=2.39$ ). Notably, none of the children reported simulator sickness following VR exposure.

The next stage of statistical analysis focused on comparing participants' attitudes before the blood sampling procedure. The analysis showed statistically significant differences between the compared groups, $H(2,57)=6.60, p<.05$, although post hoc analysis did not indicate such differences. Post hoc comparisons (Holm multiple comparisons test) revealed that participants in the active experimental group experienced more neutral attitude than their counterparts in the control group, though the results did not reach statistical significance, $p=.09, g=-0.702,95 \% \mathrm{Cl}[-1.427,-0.014]$. There were no statistically significant differences between the other groups (passive VR vs. control group: $p=.15, g=-0.274$, $95 \% \mathrm{Cl}[-0.997,0.351]$; active VR vs. passive VR: $p=.15 ; g=-0.538,95 \% \mathrm{Cl}[-1.180,0.127]$. It is worth noting, however, that across the study groups, participants responses were mostly located in the middle of the scale (see Table 1).

Table 1. Children's Emotional Reponses.

\begin{tabular}{lccccc}
\hline \multirow{2}{*}{ Condition } & \multicolumn{1}{c}{ Attitude towards blood sampling } & & \multicolumn{2}{c}{ Attitude towards blood sampling with VR } \\
\cline { 2 - 3 } \cline { 5 - 6 } & $M$ & $S D$ & & $M$ & SD \\
\hline Active VR & 5.21 & 3.00 & & 7.06 & 2.47 \\
Passive VR & 3.79 & 1.99 & & 7.79 & 1.94 \\
Control & 3.07 & 2.97 & & - & - \\
\hline
\end{tabular}

Note. 0 = strong stress and tension; $10=$ strong interest, curiosity.

The comparison of participants' attitudes in the VR groups before blood sampling revealed that there were no statistically significant differences, $t(34)=-0.98, p=.33$. In both groups, participants were interested and curious.

\section{Pain and Stress Levels}

First, we analyzed whether the levels of pain and stress differed between the experimental groups and the control group. A Kruskal-Wallis test revealed that the level of pain significantly differed among the compared groups, $H(2,57)=20.31$, $p<.001$. Post hoc comparisons (Holm multiple comparisons test) revealed that participants both in the active VR, $p<$ $.001, g=1.402,95 \% \mathrm{Cl}[0.820,1.895]$, and the passive VR group, $p<.01, g=0.935,95 \% \mathrm{Cl}[0.195,1.468]$, experienced significantly lower levels of pain when compared to the control group. When comparing levels of perceived pain between 
experimental conditions, a difference was observed, although it did not reach statistical significance, $p=.16, g=0.469$, $95 \% \mathrm{Cl}[-0.244,1.064]$. Participants in the active group reported lower pain levels.

In the next part of the analysis, the children's level of stress during blood sampling was compared. Again, the results revealed significant differences between the compared groups, $H(2,57)=15.62, p<.001$. Post hoc comparisons (Holm multiple comparisons test) revealed that the children's level of stress in the active VR group was significantly lower than in the control group, $p<.001, g=1.307,95 \% \mathrm{Cl}[0.762,1.791]$. Also, in the passive VR group, there was a difference in relation to the control group, although it did not reach statistical significance, $p=.15, g=0.420,95 \% \mathrm{Cl}[-0.255,1.044]$. Similarly, the experimental groups differed in terms of the level of stress experienced, although this difference was not statistically significant, $p=.15, g=0.842,95 \% \mathrm{Cl}[0.230,1.385]$ (see Table 2).

Table 2. Descriptive Statistics for Pain and Stress Intensity Measures.

\begin{tabular}{lccccc}
\hline \multirow{2}{*}{ Condition } & \multicolumn{2}{c}{ Visual Analogue Scale - stress intensity } & & \multicolumn{2}{c}{ Visual Analogue Scale - pain intensity } \\
\cline { 2 - 3 } \cline { 5 - 6 } & $M$ & $S D$ & 0.84 & & S \\
\hline Active VR & 0.48 & 2.42 & & 1.79 & 1.13 \\
Passive VR & 2.01 & 2.57 & & 3.34 & 1.63 \\
Control & 3.08 & &
\end{tabular}

The obtained effect sizes, both regarding the level of pain and stress, were significant, particularly when comparing the active VR group with the control group. In the present study, the effect size for the level of perceived pain in the active VR group compared to the control group was 1.40. Gershon et al. (2004) obtained an effect size of 0.66; Wolitzky et al. (2005) obtained an effect size of 1.01; and, in our previous study, we obtained an effect size of 0.86 (Piskorz \& Czub, 2018). The effect size for stress level in the active VR group compared to in the control group was 1.31 , and the effect size obtained in our previous study was 0.99 . Comparing the levels of stress and pain during blood sampling in the active VR group and the experimental group from the previous study (the difference between these studies is only in the type of VR used: stationary vs. mobile), no statistically significant differences were observed: pain: previous study $(M=1.52$, $S D=2.05)$, present study $(M=0.79, S D=1.13), t(36)=1.34, p=.19$; stress: previous study $(M=1.12, S D=1.86)$, present study $\left(M_{\text {Group } 1}=0.48, S D=0.84\right), t(36)=1.36, p=.18$. The samples did not differ in age- previous study $(M=11$ years, $S D=2.40)$ and present study $(M=12$ years, $S D=2.53)$-nor in the level of experience with blood sampling.

In the final step of this part of the analysis, we examined whether the perceived duration of the blood sampling procedure differentiated by group; the results revealed no significant differences, $H(2,57)=2.11, p=.35$.

\section{Correlation Analysis}

In the last phase of statistical analysis, correlations were conducted, this was done for all participants together, and not on per group basis. The results revealed several interesting relationships. It turned out that the more experience children had with blood sampling, the more positive attitude associated with it $(r=.38)$, and the less stress during the procedure itself $(r=-.50)$. The levels of stress and pain experienced during the procedure were also negatively correlated with children's attitude before blood sampling. The greater the tension before blood sampling, the greater the stress during the procedure $(r=-.53)$, and the greater the pain $(r=-.42)$. It is also worth noting that pain and stress levels during blood sampling were positively correlated $(r=.56$ ) (see Table 3 ).

Table 3. Correlation Matrix for Experience with Blood Sampling, Attitude Towards Blood Sampling, Pain and Stress Intensity Measures.

\begin{tabular}{lccc}
\hline & Attitude towards blood sampling & Pain & Stress \\
\hline Experience with blood sampling & $.38^{*}$ & -.18 & $-.50^{* *}$ \\
Attitude towards blood sampling & - & $-.42^{*}$ & $-.53^{\star *}$ \\
Pain & - & - & $.56^{* *}$ \\
\hline
\end{tabular}

Note. ${ }^{*} p<.01,{ }^{* *} p<.001$. 


\section{Discussion}

The obtained results confirm the effectiveness of VR as a distractor from painful stimuli. Focusing attention on the VR game significantly reduced participants' level of stress and pain. Compared to the control group, the levels of stress was 84.4\% lower in the active VR group and 34.7\% lower in the passive VR group. At the same time, compared to the control group, pain levels decreased by $76.4 \%$ in the active VR group and by $56.3 \%$ in the passive VR group. It is worth noting that blood sampling is a medical procedure not associated with a high degree of pain; rather, it is more uncomfortable than particularly painful. Undoubtedly, this procedure is not pleasant-indeed rather stressful for patients-especially children. The relatively low stress levels observed in this study can likely be explained by the fact that our sample was comprised of nephrologically ill children who already had considerable experience with blood sampling.

Regarding the passive VR group, the obtained results, although slightly lower than in the active VR group, were also significant (pain $=0.94$; stress $=0.42$ ). Interestingly, the obtained effect sizes clearly exceeded effect sizes from our previous study. It is puzzling, taking into account that the game used in the current study-although based on the same principles - was less visually attractive than the previous one due to all of the levels having similar, unchanging graphics. Perhaps the use of mobile VR meant that the whole procedure was gentler and calmer. The experimenters did not need to be present in the treatment room during the blood sampling procedure because the equipment handling was much easier. Additionally, the medical staff were not preoccupied with the presence of other people, which likely had a positive impact on the entire procedure.

The analysis of the results, however, did not show any particular differences in levels of perceived pain and stress between groups with active versus passive VR. Although differences between these groups were revealed in the intensity of pain and stress during the procedure, and thus in the level of pain and stress reduction in relation to the control group, these differences were not statistically significant. However, when comparing experienced stress between experimental groups, the effect size was significant (0.84), suggesting that it is worth further investigating different kinds of VR distractions in order to maximally reduce children's discomfort during painful medical procedures.

The question arises as to why there was only a small difference $(g=0.47)$ in the level of perceived pain between the experimental conditions. One possibility is merely the type of medical procedure utilized in this study. Blood sampling is a short and not exceedingly painful procedure, which is why the choice of VR environment might not be that important. Alternatively, mere VR immersion might be important. We tried to make both environments as similar as possible, differing only in terms of the level of activity required. The subjects rated their engagement in each VR environment nearly identically_as highly engaging. It is likely that in the case of a longer and more painful medical procedure, differentiation between VR environment would have greater significance. In particular, some studies have demonstrated the advantages of active over passive VR distraction (Dahlquist et al., 2007).

The results revealed significant main effect for difference between the groups in their attitude before blood sampling, although none of the post-hoc comparisons between specific groups reached significance. These conflicting results may be due to the relatively small sample size. However, it is worth attempting to explain certain differences in children's emotions in the active VR group compared to the control group. On the one hand, these differences could be explained by the lack of full randomization in the assignment to groups. A more likely explanation, however, is that the participants in the experimental group expected to experience non-standard blood sampling. They anticipated that the medical procedure would have a different course than usual. The study procedure required the experimenter to inform the participants about how the experiment would be carried out. In addition, before the start of the study, children in the active VR group practiced using the interface and became familiar with the game. In the case of the passive VR group, children became familiar with the video that was going to be shown to them. In our opinion, the differences in experienced emotions were likely a result of participants' attitudes toward the study as opposed to differences related to perceptions of blood sampling. Children from the active VR group had more positive attitudes and were more curious because they were excited about a new experience. Information on the use of VR during blood sampling is part of this procedure. VR cannot be used without participants' informed consent.

Among existing research, the present study stands out because of the use of mobile VR technology, which is now available to a wide range of patients. Achieving an analgesic effect using cheap VR equipment has broad applications for medical practice. Future studies should investigate the effectiveness of distraction using VR for other types of medical procedures. They could also use physiological indicators of stress (e.g., cortisol level), which was not possible in this study due to the short duration of the procedure. Another challenge is to develop a research study in which even younger 
children (3-5 years old) could participate. Despite its limitations, our study revealed that mobile VR distraction reduced needle pain and stress in children, and that MOT task can be effectively implemented as a method of VR attention distraction. We hope that this paper will garner further attention regarding the possible applications of mobile VR technology as an analgesic tool in medical procedures, particularly for children.

\section{Acknowledgement}

The project was supported by funds from the Polish National Science Centre (MINIATURA 1 scholarship 2017/01/X/HS6/01935 to Joanna Piskorz).

\section{References}

Allison, D., Wills, B., Bowman, D., Wineman, J., \& Hodges, L. F. (1997). The virtual reality gorilla exhibit. IEEE Computer Graphics and Applications, 17(6), 30-38. https://doi.org/10.1109/38.626967

Alvarez, G. A., \& Scholl, B. J. (2005). How does attention select and track spatially extended objects? New effects of attentional concentration and amplification. Journal of Experimental Psychology: General, 134(4), 461-476.

https://doi.org/10.1037/0096-3445.134.4.461

Birnie, K. A., Noel, M., Parker, J. A., Chambers, C. T., Uman, L. S., Kisely, S. R., \& McGrath, P. J. (2014). Systematic review and meta-analysis of distraction and hypnosis for needle-related pain and distress in children and adolescents. Journal of Pediatric Psychology, 39(8), 783-808. https://doi.org/10.1093/jpepsy/jsu029

Chan, E. A., Chung, J. W., Wong, T. K., Lien, A. S., \& Yang, J. Y. (2007). Application of a virtual reality prototype for pain relief of pediatric burn in Taiwan. Journal of Clinical Nursing, 16(4), 786-793. https://doi.org/10.1111/j.1365-

2702.2006.01719.x

Chirico, A., Lucidi, F., De Laurentiis, M., Milanese, C., Napoli, A., \& Giordano, A. (2016a). Virtual reality in health system: Beyond entertainment. A mini-review on the efficacy of VR during cancer treatment. Journal of Cellular Physiology, 231(2), 275-287. https://doi.org/10.1002/jcp.25117

Chirico, A., D’Aiuto, M., Pinto, M., Milanese, C., Napoli, A., Avino, F., lodice, G., Russo, G., De Laurentiis, M., Ciliberto, G., Giordano, A., \& Lucidi, F. (2016b). The elapsed time during a virtual reality treatment for stressful procedures: A pool analysis on breast cancer patients during chemotherapy. In G. De Pietro, L. Gallo, R. J. Howlett, \& L. C. Jain (Eds.), Intelligent Interactive Multimedia Systems and Services 2016 (pp. 731-738). Springer.

Cohen, L. L., Cousins, L. A., \& Martin, S. R. (2014). Procedural pain distraction. In P. J. McGrath, B. J. Stevens, S. M. Walker, \& W. T. Zempsky (Eds.), Oxford textbook of paediatric pain (pp. 553-559). Oxford University Press.

Czub, M., \& Piskorz, J. (2018). Body movement reduces pain intensity in virtual reality-based analgesia. International Journal of Human-Computer Interaction, 34(11), 1045-1051. https://doi.org/10.1080/10447318.2017.1412144

Dahlquist, L. M., McKenna, K. D., Jones, K. K., Dillinger, L., Weiss, K. E., \& Ackerman, C. S. (2007). Active and passive distraction using a head-mounted display helmet: Effects on cold pressor pain in children. Health Psychology, 26(6), 794-801. https://doi.org/10.1037/0278-6133.26.6.794

Das, D. A., Grimmer, K. A., Sparnon, A. L., McRae, S. E., \& Thomas, B. H. (2005). The efficacy of playing a virtual reality game in modulating pain for children with acute burn injuries: A randomized controlled trial [ISRCTN87413556]. BMC Pediatrics, 5, Article 1. https://doi.org/10.1186/1471-2431-5-1

Eccleston, C., \& Crombez, G. (1999). Pain demands attention: A cognitive-affective model of the interruptive function of pain. Psychological Bulletin, 125(3), 356-366. https://doi.org/10.1037/0033-2909.125.3.356 
Fougnie, D., \& Marois, R. (2006). Distinct capacity limits for attention and working memory: Evidence from attentive tracking and visual working memory paradigms. Psychological Science, 17(6), 526-534. https://doi.org/10.1111/j.14679280.2006.01739.x

Fowler-Kerry, S., \& Lander, J. R. (1987). Management of injection pain in children. PAIN, 30(2), 169-175. https://doi.org/10.1016/0304-3959(87)91072-4

Fradet, C., McGrath, P. J., Kay, J., Adams, S., \& Luke, B. (1990). A prospective survey of reactions to blood tests by children and adolescents. PAIN, 40(1), 53-60. https://doi.org/10.1016/0304-3959(90)91050-S

Gatchel, R. J., Peng, Y. B., Peters, M. L., Fuchs, P. N., \& Turk, D. C. (2007). The biopsychosocial approach to chronic pain: Scientific advances and future directions. Psychological Bulletin, 133(4), 581-624. https://doi.org/10.1037/00332909.133.4.581

Gershon, J., Zimand, E., Pickering, M., Rothbaum, B. O., \& Hodges, L. (2004). A pilot and feasibility study of virtual reality as a distraction for children with cancer. Journal of the American Academy of Child \& Adolescent Psychiatry, 43(10), 1243-1249. https://doi.org/10.1097/01.chi.0000135621.23145.05

Gold, J. I., \& Mahrer, N. E. (2017). Is virtual reality ready for prime time in the medical space? A randomized control trial of pediatric virtual reality for acute procedural pain management. Journal of Pediatric Psychology, 43(3), 266-275. https://doi.org/10.1093/jpepsy/jsx129

Gold, J. I., Kim, S. H., Kant, A. J., Joseph, M. H., \& Rizzo, A. S. (2006). Effectiveness of virtual reality for pediatric pain distraction during IV placement. CyberPsychology \& Behavior, 9(2), 207-212. https://doi.org/10.1089/cpb.2006.9.207

Goodenough, B., Kampel, L., Champion, G. D., Laubreaux, L., Nicholas, M. K., Ziegler, J. B., \& Mclnerney, M. (1997). An investigation of the placebo effect and age-related factors in the report of needle pain from venipuncture in children. PAIN, 72(3), 383-391. https://doi.org/10.1016/S0304-3959(97)00062-6

Hoffman, H. G., Chambers, G. T., Meyer, W. J., Ill., Arceneaux, L. L., Russell, W. J., Seibel, E. J., Richards, T. L., Sharar, S. R., \& Patterson, D. R. (2011). Virtual reality as an adjunctive non-pharmacologic analgesic for acute burn pain during medical procedures. Annals of Behavioral Medicine, 41(2), 183-191. https://doi.org/10.1007/s12160-010-9248-7

Hoffman, H. G., Garcia-Palacios, A., Kapa, V., Beecher, J., \& Sharar, S. R. (2003). Immersive virtual reality for reducing experimental ischemic pain. International Journal of Human-Computer Interaction, 15(3), 469-486.

https://doi.org/10.1207/S15327590IJHC1503_10

Hoffman, H. G., Richards, T. L., Bills, A. R., Van Oostrom, T., Magula, J., Seibel, E. J., \& Sharar, S. R. (2006). Using fMRI to study the neural correlates of virtual reality analgesia. CNS Spectrums, 11(1), 45-51.

https://doi.org/10.1017/S1092852900024202

Hoffman, H. G., Seibel, E. J., Richards, T. L., Furness, T. A., III., Patterson, D. R., \& Sharar, S. R. (2006). Virtual reality helmet display quality influences the magnitude of virtual reality analgesia. The Journal of Pain, 7(11), 843-850.

https://doi.org/10.1016/j.jpain.2006.04.006

Hoffman, H. G., Sharar, S. R., Coda, B., Everett, J. J., Ciol, M., Richards, T., \& Patterson, D. R. (2004). Manipulating presence influences the magnitude of virtual reality analgesia. PAIN, 111(1), 162-168.

https://doi.org/10.1016/j.pain.2004.06.013

Indovina, P., Barone, D., Gallo, L., Chirico, A., De Pietro, G., \& Giordano, A. (2018). Virtual reality as a distraction intervention to relieve pain and distress during medical procedures. The Clinical Journal of Pain, 34(9), 858-877. https://doi.org/10.1097/AJP.0000000000000599

Jacobson, R. M., Swan, A., Adegbenro, A., Ludington, S. L., Wollan, P. C., Poland, G. A., \& Vaccine Research Group. (2001). Making vaccines more acceptable-methods to prevent and minimize pain and other common adverse events associated with vaccines. Vaccine, 19(17-19), 2418-2427. https://doi.org/10.1016/S0264-410X(00)00466-7 
Jeffs, D., Dorman, D., Brown, S., Files, A., Graves, T., Kirk, E., Meredith-Neve, S., Sanders, J., White, B., \& Swearingen, C. J. (2014). Effect of virtual reality on adolescent pain during burn wound care. Journal of Burn Care \& Research, 35(5), 395408. https://doi.org/10.1097/BCR.0000000000000019

Kelley, M. L., Jarvie, G. J., Middlebrook, J. L., McNeer, M. F., \& Drabman, R. S. (1984). Decreasing burned children's pain behavior: Impacting the trauma of hydrotherapy. Journal of Applied Behavior Analysis, 17(2), 147-158.

https://doi.org/10.1901/jaba.1984.17-147

Kenney, M. P., \& Milling, L. S. (2016). The effectiveness of virtual reality distraction for reducing pain: A meta-analysis. Psychology of Consciousness: Theory, Research, and Practice, 3(3), 199-210. https://doi.org/10.1037/cns0000084

Kirby, K. N., \& Gerlanc, D. (2013). BootES: An R package for bootstrap confidence intervals on effect sizes. Behavior research methods, 45(4), 905-927.

MacLaren, J. E., \& Cohen, L. L. (2005). A comparison of distraction strategies for venipuncture distress in children. Journal of Pediatric Psychology, 30(5), 387-396. https://doi.org/10.1093/jpepsy/jsi062

Magora, F., Cohen, S., Shochina, M., \& Dayan, E. (2006). Virtual reality immersion method of distraction to control experimental ischemic pain. The Israel Medical Association Journal, 8(4), 261-265.

Manne, S. L., Redd, W. H., Jacobsen, P. B., Gorfinkle, K., Schorr, O., \& Rapkin, B. (1990). Behavioral intervention to reduce child and parent distress during venipuncture. Journal of Consulting and Clinical Psychology, 58(5), 565-572. https://doi.org/10.1037/0022-006X.58.5.565

Mason, S., Johnson, M. H., \& Woolley, C. (1999). A comparison of distractors for controlling distress in young children during medical procedures. Journal of Clinical Psychology in Medical Settings, 6(3), 239-248.

https://doi.org/10.1023/A:1026235620538

McCaul, K. D., \& Malott, J. M. (1984). Distraction and coping with pain. Psychological Bulletin, 95(3), 516-533. https://doi.org/10.1037/0033-2909.95.3.516

Melzack, R. (2001). Pain and the neuromatrix in the brain. Journal of Dental Education, 65(12), 1378-1382. http://www.jdentaled.org/content/65/12/1378

National Academies of Sciences, Engineering, and Medicine. (2017). Pain management and the opioid epidemic: Balancing societal and individual benefits and risks of prescription opioid use. The National Academies Press. https://doi.org/10.17226/24781

Nilsson, S., Enskär, K., Hallqvist, C., \& Kokinsky, E. (2013). Active and passive distraction in children undergoing wound dressings. Journal of Pediatric Nursing, 28(2), 158-166. https://doi.org/10.1016/j.pedn.2012.06.003

Nilsson, S., Finnström, B., Kokinsky, E., \& Enskär, K. (2009). The use of Virtual Reality for needle-related procedural pain and distress in children and adolescents in a paediatric oncology unit. European Journal of Oncology Nursing, 13(2), 102-109. https://doi.org/10.1016/j.ejon.2009.01.003

O'Hearn, K., Landau, B., \& Hoffman, J. E. (2005). Multiple object tracking in people with Williams syndrome and in normally developing children. Psychological science, 16(11), 905-912. https://doi.org/10.1111/j.1467-9280.2005.01635.x

Piskorz, J., \& Czub, M. (2018). Effectiveness of a virtual reality intervention to minimize pediatric stress and pain intensity during venipuncture. Journal for Specialists in Pediatric Nursing, 23(1), Article e12201.

https://doi.org/10.1111/jspn.12201

Ploghaus, A., Narain, C., Beckmann, C. F., Clare, S., Bantick, S., Wise, R., Matthews, P. M., Rawlins, J. N. P., \& Tracey, I. (2001). Exacerbation of pain by anxiety is associated with activity in a hippocampal network. The Journal of Neuroscience, 21(24), 9896-9903. https://doi.org/10.1523/JNEUROSCI.21-24-09896.2001 
Postle, B. R., D'Esposito, M., \& Corkin, S. (2005). Effects of verbal and nonverbal interference on spatial and object visual working memory. Memory \& Cognition, 33(2), 203-212. https://doi.org/10.3758/BF03195309

Powers, S. W., Blount, R. L., Bachanas, P. J., Cotter, M. W., \& Swan, S. C. (1993). Helping preschool leukemia patients and their parents cope during injections. Journal of Pediatric Psychology, 18(6), 681-695.

https://doi.org/10.1093/jpepsy/18.6.681

Rehman, A. U., Kihara, K., Matsumoto, A., \& Ohtsuka, S. (2015). Attentive tracking of moving objects in real 3D space. Vision Research, 109(Part A), 1-10. https://doi.org/10.1016/j.visres.2015.02.004

Schneider, S. M., \& Hood, L. E. (2007). Virtual reality: A distraction intervention for chemotherapy. Oncology Nursing Forum, 34(1), 39-46. https://doi.org/10.1188/07.ONF.39-46

Schneider, S. M., Kisby, C. K., \& Flint, E. P. (2011). Effect of virtual reality on time perception in patients receiving chemotherapy. Supportive Care in Cancer, 19(4), 555-564. https://doi.org/10.1007/s00520-010-0852-7

Scholl, B. J. (2009). What have we learned about attention from multiple object tracking (and vice versa)? In D. Dedrick \& L. Trick (Eds.), Computation, cognition, and Pylyshyn (pp. 49-77). MIT Press.

Triberti, S., Repetto, C., \& Riva, G. (2014). Psychological factors influencing the effectiveness of virtual reality-based analgesia: A systematic review. Cyberpsychology, Behavior, and Social Networking, 17(6), 335-345.

https://doi.org/10.1089/cyber.2014.0054

Trick, L. M., Guindon, J., \& Vallis, L. A. (2006). Sequential tapping interferes selectively with multiple-object tracking: Do finger-tapping and tracking share a common resource? The Quarterly Journal of Experimental Psychology, 59(7), 11881195. https://doi.org/10.1080/17470210600673990

Villemure, C., \& Bushnell, C. M. (2002). Cognitive modulation of pain: How do attention and emotion influence pain processing? PAIN, 95(3), 195-199. https://doi.org/10.1016/S0304-3959(02)00007-6

Windich-Biermeier, A., Sjoberg, I., Dale, J. C., Eshelman, D., \& Guzzetta, C. E. (2007). Effects of distraction on pain, fear, and distress during venous port access and venipuncture in children and adolescents with cancer. Journal of Pediatric Oncology Nursing, 24(1), 8-19. https://doi.org/10.1177/1043454206296018

Wolitzky, K., Fivush, R., Zimand, E., Hodges, L., \& Rothbaum, B. O. (2005). Effectiveness of virtual reality distraction during a painful medical procedure in pediatric oncology patients. Psychology \& Health, 20(6), 817-824.

https://doi.org/10.1080/14768320500143339

\section{Correspondence to:}

Joanna Ewa Piskorz

Institute of Psychology, University of Wroclaw

ul. Dawida 1

Wroclaw 50527

Poland

Email: psychologia(at)uwr.edu.pl

Tel: +48 713672001 w. 126

Editorial record: First submission received on January 24, 2019. Revisions received on September 26, 2019, January 21, 2020 and January 24, 2020. Accepted for publication on January 24, 2020.

Editor in charge: Kristian Daneback 


\section{About Authors}

Joanna Ewa Piskorz, Ph.D. is an Assistant Professor of Psychology at University of Wroclaw. Since 2000 is researching VR use in psychology. Since 2012 works in "VR4Health" project, studying VR use in pain alleviation, both in experimental pain paradigms, and clinical settings.

Marcin Czub, Ph.D. is an Assistant Professor at the Institute of Psychology, University of Wroclaw, Poland. Lead researcher in "VR4Health" - a research project on Virtual Reality and pain perception. His research and teaching are focused on body perception, cognitive psychology, pain perception, and virtual reality. Laureate of Foundation for Polish Science prize for educational project "Being an avatar - Virtual Reality and the psychology of body perception".

Beata Šulžickaja, holder of a master's degree in psychology, graduated in 2015. Deeply interested in neuroscience and the therapeutic potential of Virtual Reality in reducing pain, stimulating intellectual capacity and improving mental health. In collaboration with VR4Health and the University of Wroclaw since 2017.

Katarzyna Kiliś-Pstrusińska, Professor of Medicine, M.D., Ph.D., psychologist, Wroclaw Medical University. Interested in health related quality of life in children with chronic kidney diseases, collaborating with several centers of pediatric nephrology and pediatrics. 